\title{
Australian Journal of

\section{Effect of different gamma radiation doses on the germination and seedling growth of wheat and triticale cultivars}

\author{
Francisco Javier Di Pane ${ }^{1}$, Silvia Concepción Lopez ${ }^{2}$, Miguel Ángel Cantamutto ${ }^{3}$, Marisa Beatriz \\ Domenech $^{1}$, Mauricio Castro-Franco ${ }^{4}$
}

${ }^{1}$ Instituto Nacional de Tecnología Agropecuaria INTA, CEI Barrow

${ }^{2}$ Comisión Nacional de Energía Atómica (CNEA)

${ }^{3}$ Estación Experimental Agropecuaria Hilario Ascasubi

${ }^{4}$ Consejo Nacional de Investigaciones Científicas y Tecnicas (CONICET)

\section{*Corresponding author: dipane.francisco@inta.gob.ar}

\section{Abstract}

Plan breeding of wheat and triticale in Argentina is based on the objective of improving an individual crop, with respect to resistance to drought stress. The use of gamma radiation holds promise for physiological crop improvement. The objective of this study was to determine and compare the effect of different gamma radiation doses on the germination and seedling growth of Argentine wheat and triticale cultivars. Seeds of wheat cv. Baguette 10 and triticale cv. Espinillo INTA were irradiated at doses of 0 , $50,200,400,550,700,850$ and $1000 \mathrm{~Gy} \mathrm{~s}^{-1}$. The final germination percentage (FGP), sprout length (SL) and median lethal dose $\left(\mathrm{LD}_{50}\right)$ were used as metrics of germination, seedling growth and lethal dose, respectively. Two experimental designs were used. First, a completely randomized factorial was used to compare the effect of the doses within species by using ANOVA; second, a completely repeated measures design was used to evaluate the effect of days after germination on plant survival by species using a mixed linear model. The results suggest that at the early germination stage, gamma radiation limited root growth and stem length. The FGP of wheat seeds was significantly affected by gamma radiation at a dose of $550 \mathrm{~Gy}$, whereas triticale seeds were significantly affected at a dose of $700 \mathrm{~Gy}$. The SL of both species was similarly affected at $50 \mathrm{~Gy}$. The stem mortality of wheat and triticale seeds increased at an increasing gamma radiation dose and days after germination. Finally, the $\mathrm{LD}_{50}$ value for wheat and triticale seeds was $\sim 450 \mathrm{~Gy}$. These results might be useful to set a benchmark of the effect of the gamma radiation dose to induce mutations in wheat and triticale seeds from Argentine cultivars.

Keywords: Argentina, gamma radiation, median lethal dose, plant breeding, wheat, triticale. Abbreviations: Gy_Gray; cv_Cultivar, FGP_Final germination percentage; SL_Sprout length; LD $50 \_$Median lethal dose

\section{Introduction}

Argentina is an important winter wheat and triticale producer in the world (Wrigley et al., 2016). This country produces around 16.5 million tons of wheat per year in an area of $\sim 5.4$ million hectares and $\sim 122$ tons of triticale per year in $\sim 45$ thousand hectares (Paccapelo et al., 2017; SIIA, 2016). Only $\sim 6$ million tons of wheat is for domestic consumption while the rest is exported, whereas the production of triticale is entirely for domestic supply (FAOSTAT, 2015). These crops are cultivated in a region located from 26 to $39^{\circ} \mathrm{S}$ and from 57 to $65^{\circ} \mathrm{W}$.

In Argentina, the most important limiting factors in wheat and triticale production are drought stress and variable weather conditions (Abbate et al., 2004; Castro et al., 2011). Particularly, drought causes a harmful effect on germination and seedling growth of both wheat and triticale (Agha et al., 2017; Blum et al., 1980). Hence, Argentine wheat and triticale breeding programs have studied physiological characteristics to optimize the selection process and evaluate drought-tolerant genotypes (Araus et al., 2002;
Miazek et al., 2001; Slafer and Andrade, 1989). The response of plants to drought involves a complex physico-chemical process in which macro- and micro-molecules such as proteins, lipids, hormones, ions, minerals, free radicals and nucleic acids (RNA, micro-RNA and DNA) interact simultaneously (Slafer et al., 2005). This complexity makes difficult the selection of drought-tolerant genotypes at early phenological stages (Setter and Waters, 2003). Thus, to increase the effectiveness of wheat cultivar breeding programs, it would be necessary to develop, assess and report novel strategies in plant breeding techniques.

Gamma radiation of seeds has become a recent technological technique in plant breeding (Ahloowalia and Maluszynski, 2001). This radiation has been shown to alter both germination and seedling growth, as well as protein synthesis, hormonal balance, leaf gas exchange, evaporation and enzymatic activities (Jan et al., 2012). The biological effect of gamma rays is based on the interaction with atoms and molecules in the plant cell to generate free radicals (Wi 
et al., 2007). The magnitude of these alterations depends on the doses and intensity of gamma rays (Irfaq and Nawab, 2001). In wheat, numerous studies have reported that gamma radiation of seeds causes physiological changes such as inhibition of seed germination and seedling growth (Borzouei et al., 2010; Melki and Marouani, 2010). However, this effect has not yet been assessed in wheat cultivar seeds obtained by Argentine wheat breeding programs. On the other hand, few studies have reported the effect of radiation in triticale (Pandini et al., 1997). In this context, it would be interesting to study the effect of gamma radiation on the physiological process during germination and seedling growth of Argentine wheat and triticale seeds.

Thus, the aim of this study was to determine and compare the effect of different gamma radiation doses on the germination and seedling growth of Argentine wheat and triticale cultivars. The germination rate, median lethal dose and sprout length were measured. The results might be useful to set a benchmark of the effect of the gamma radiation dose to induce mutations in wheat and triticale seeds from Argentine cultivars.

\section{Results and discussion}

\section{Effect of the radiation dose on the germination rate}

Figure 1 shows images of wheat and triticale irradiated seeds in a germinating experiment (data measured on the 6 th day after germination), whereas Figure 2 shows the results of the effects of the radiation doses on the final germination percentage (FGP) and the sprout length (SL) for both species.

The FGP of both species was significantly affected by gamma radiation. However, the magnitude of the effect in wheat seeds led to different results compared with other reports. The FGP of wheat seeds significantly decreased when the radiation dose was equal to or higher than $550 \mathrm{~Gy}$ and decreased by $75 \%$ at 1000 Gy. In contrast, Wang et al. (2012) and Wang and You (2000) reported that the FGP of wheat seeds decreased to $0 \%$ and $23 \%$, respectively, when the radiation dose was higher than 600 Gy. Singh and Balyan (2009) reported that the germination rate of wheat seeds decreased to $20 \%$ at $400 \mathrm{~Gy}$.

The FGP of triticale was affected by the gamma radiation in a magnitude similar to that observed in wheat seeds. In contrast to that found by Sapra and Constantin (1978), who reported that the FGP of triticale decreased to $50 \%$ at 500 Gy, in the present study, the FGP of triticale significantly decreased when radiation was equal to or higher than 700 Gy and decreased by $75 \%$ at $1000 \mathrm{~Gy}$.

Figure 3 compares the effects of the radiation doses on FGP and $S L$ in both species. In general, the effect of the radiation dose on FGP was similar in both species: the FGP decreased remarkably at $700 \mathrm{~Gy}$.

Our results confirm that the increase in the dose of gamma rays leads to a reduced FGP in both species. They also show that the effect of gamma radiation was greater in the roots than in the aerial part of seedlings (Fig. 1). This is in agreement with the results of Wang et al. (2012), who suggested that the effect of the dose of gamma rays on the germination rate of wheat is due to morphological and physiological changes in the roots.

\section{Effect of the radiation dose on seedling growth}

The effect of gamma radiation on SL was significantly different between $0 \mathrm{~Gy}$ and doses higher than $50 \mathrm{~Gy}$. This difference was similar between species (Figures 2 and 3). In contrast, Singh and Datta (2010) and Singh et al. (2013) reported that the dry matter weight increased at $700 \mathrm{~Gy}$ and that the effect on the SL of wheat was insignificant at 500 Gy. In another study, these authors found that at $50 \mathrm{~Gy}$, root biomass and length were increased. Wang et al. (2012) reported that the SL of wheat decreased progressively and showed a lethal effect on roots at 600 Gy. Particularly for triticale, Sapra and Constantin (1978) reported that SL decreased at $400 \mathrm{~Gy}$. In the present study, we concluded that the sensitivity of Argentine wheat and triticale seeds to gamma radiation was higher in roots than in the aerial parts. This might be attributed to the genetic characteristics of species which determine the sensitivity to gamma radiation.

\section{Effect of the radiation dose on the germination time}

Figure 4 shows the effect of three representative doses and germination time on species survival percentage. Stem mortality increased with increasing radiation doses and germination time. Specifically, stem mortality after twelve days of germination in plants irradiated with doses higher than 550 Gy was $80 \%$. This result is novel because of two aspects. First, only few works have determined the effects of radiation on stem survival (Singh et al., 2013; Sparrow et al., 1971), and have shown different sensitivity to gamma radiation between germination and stem survival. Second, it confirms the high sensitivity of wheat and triticale seeds to gamma radiation, even at twelve days after germination. This sensitivity could be attributed to the effect of gamma radiation on roots, indicating a potential sensitivity of stems after twelve days of germination. Thus, the changes in sensitivity were probably due to the self-repair function of the irradiated organism (Wang et al., 2012). Also, it is widely known that a decrease both in roots and stems during germination could be related to a decrease in water use and nutrient uptake, both of which limit seedling growth.

\section{Median lethal dose estimate}

The $\mathrm{LD}_{50}$ estimate for wheat and triticale seeds was around $\sim 450$ Gy (Fig. 5). In general, there is no agreement on the $\mathrm{LD}_{50}$ value for wheat seeds. Numerous studies have reported $\mathrm{LD}_{50}$ values for wheat seeds lower than those determined in the present study. Studies conducted by Sparrow et al. (1971) and Singh and Balyan (2009) reported $L_{50}$ values for wheat seeds of 250 and $350 \mathrm{~Gy}$, respectively. However, in those studies, the effect of germination time was not taken into account, although this was a key factor to determine sensitivity in this study. Our results are in agreement with 

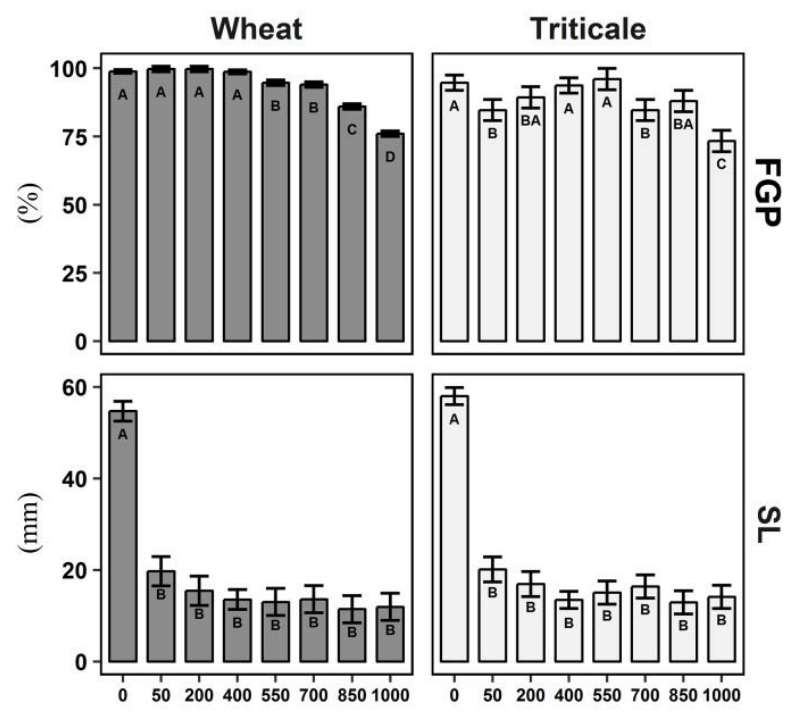

Gamma Radiation Dose (Gy)

Fig 1. Comparison of the effect of gamma radiation doses on final germination percentage (FGP) and sprout length (SL), in wheat and triticale irradiated seeds. Data refer to mean values \pm standard error. Means followed by the same letter are not significantly different $(\alpha=0.05)$.

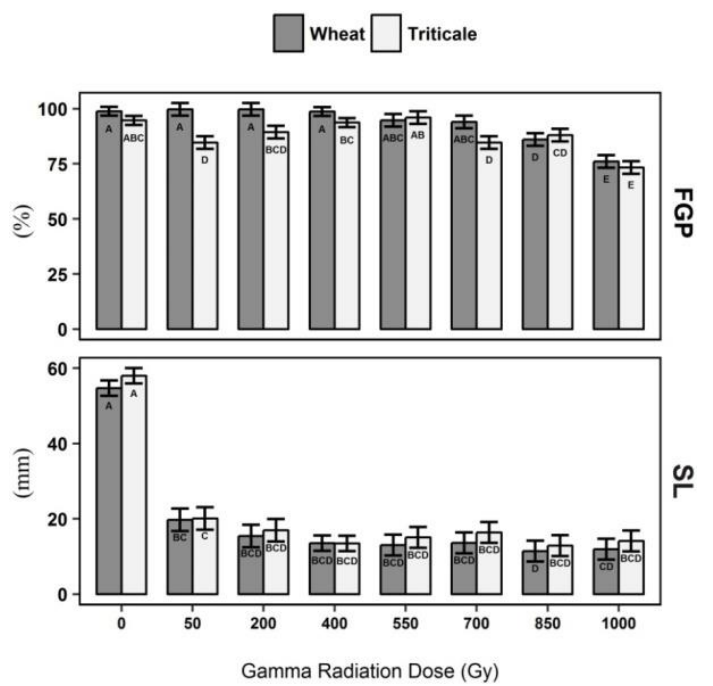

Fig 2. Comparison of the differences in final germination percentage (FGP) and sprout length (SL), between wheat and triticale irradiated seeds. Data refer to mean values \pm standard error. Means followed by the same letter are not significantly different $(\alpha=$ 0.05).

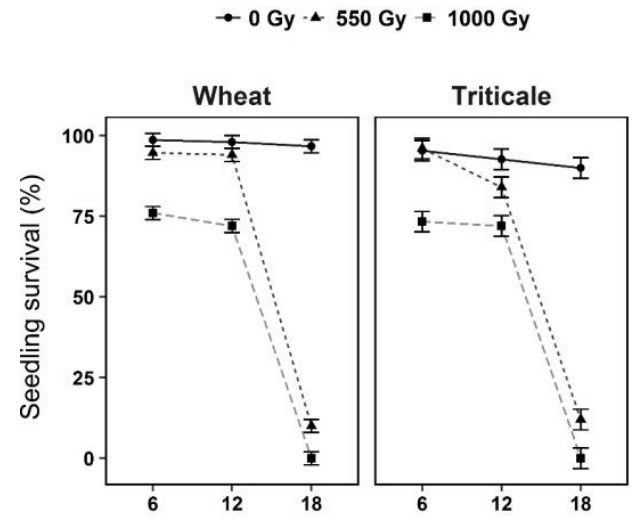

Days After Germination

Fig 4. Comparison of the effect of gamma radiation doses and germination time on the survival of irradiated wheat and triticale plants. Point data refer to mean values \pm standard error. 


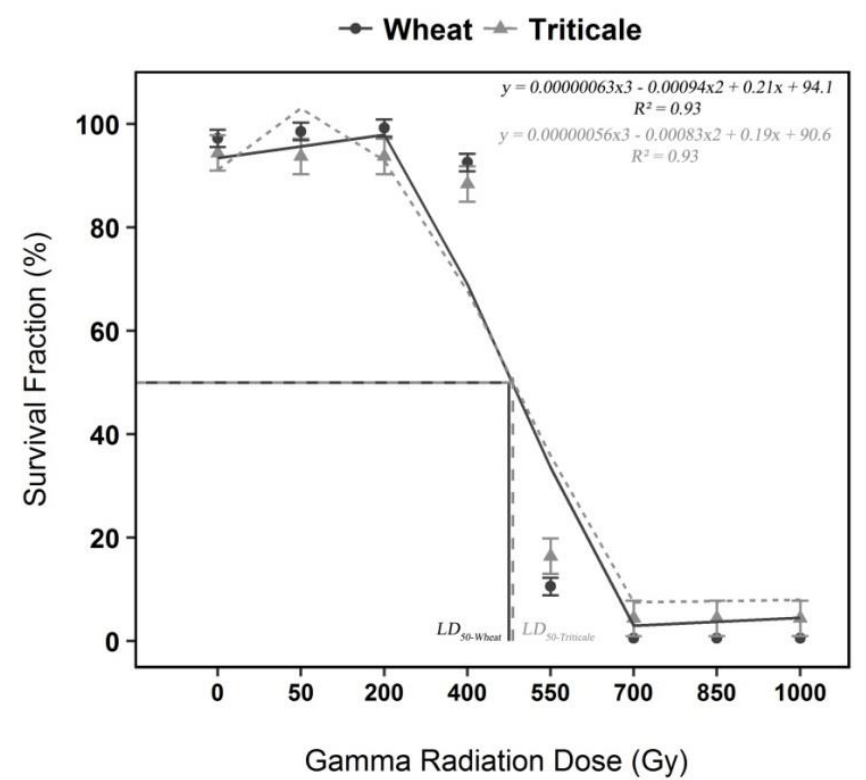

Fig 3. Comparison of the median lethal dose $\left(\mathrm{LD}_{50}\right)$ estimate in wheat and triticale irradiated seeds. Point data refer to mean values \pm standard error.

the findings of Sapra and Constantin (1978), who reported a value of $L D_{50}$ of $\sim 460 \mathrm{~Gy}$ for triticale.

\section{Materials and Methods}

\section{Seeds and gamma radiation doses}

Seeds of wheat cv. Baguette 10 and triticale cv. Espinillo INTA were used for the study. These cultivars are commonly selected for experimental use because their genetic, physiological and yield characteristics are representative of the cultivars more sown in Argentina (Mirabella et al., 2016; Miralles et al., 2007). Baguette 10 is an hexaploid cultivar obtained by the Nidera breeding program (Vanzetti et al., 2013), whereas Espinillo INTA is an hexaploid cultivar obtained by the National Institute of Agriculture Technology of Argentina (INTA) and the CIMMYT breeding program (Donaire et al., 2016).

Before radiation treatments, all seeds were at similar environmental conditions. They were stored on paper envelopes at ambient temperature in the seed laboratory at Barrow Experimental Station of INTA. Seed moisture was around $13 \%$, and seeds were not older than six months after harvest.

Wheat and triticale seeds were irradiated using gamma ${ }^{60} \mathrm{C}_{0}$ at the laboratory of the National Atomic Energy Commission (CNEA), Argentina. The samples were divided into three sets, with 50 seeds per species. Seeds were irradiated at doses of 0 (non-irradiated), 50, 200, 400, 550, 700, 850 and $1000 \mathrm{~Gy}$ $\mathrm{s}^{-1}$.

\section{Analysis of the effect of gamma radiation on germination}

At the Barrow Experimental Station of INTA, the irradiated seeds were placed in germination test paper for six days at $22.5^{\circ} \mathrm{C}$ according to ISTA (ISTA, 1985).

The final germination percentage (FGP) was calculated as a metric of seed viability. FGP has been widely used in studies on wheat seeds but not in triticale (Borzouei et al., 2010;
Melki and Marouani, 2010; Wang et al., 2012). Hence, FGP would allow comparing results in wheat seeds, contributing to the discussion of the effects of gamma radiation on germination, whereas, in triticale, it could be used as a reference for further plant breeding studies.

\section{Analysis of the effect of gamma radiation on seedling growth}

Sprout length (SL) was used as a metric for seedling growth. $\mathrm{SL}$ was measured in three samples of seven seedlings per species, on the sixth day after germination. SL has also been often used in studies on the effect of gamma radiation in wheat but not in triticale seeds.

\section{Estimation of median lethal dose}

The metric used to determine the lethal gamma radiation dose in wheat and triticale seed survival was the median lethal dose $\left(L_{50}\right)$. $L D_{50}$ was calculated as the lethal gamma radiation dose at which the fraction of surviving plants was lower than $50 \%$. The survival fraction was calculated as follows:

Survival Fraction $=\frac{N P V_{18 d}}{N P T_{i}} * 100$

where $N P V_{18 d}$ is the number of plants surviving on the 18th day after germination and $N P T_{i}$ is the total number of plants.

\section{Statistical analysis}

Two experimental designs were used: a completely randomized factorial design and a repeated measures design. In the completely randomized factorial design, the factors were species (wheat and triticale) and gamma radiation (eight levels) with three replications. The Least Significant Difference $(L S D)$ test $(p<0.05)$ was used to determine the differences in the average of FGP and SL between irradiated and non-irradiated seeds. The repeated 
measures design had three measures at 6,12 and 18 days after germination and the treatments were the levels of gamma radiation. The effects of the treatment within species, including the radiation dose $x$ species interaction, were compared. ANOVA was applied according to the following linear model:

$y_{i j k}=\mu+E s p_{j}+g(E s p)_{i(j)}+\varepsilon_{i j k}$

where $y_{i j k}$ represents FGP or SL measured in species $i$ exposed to the gamma radiation dose $j ; \mu$ is the general mean; $E s p_{j}$ is the species effect; $g(E s p)_{i(j)}$ is the species effect within the gamma radiation dose; and $\varepsilon_{i j k}$ is the random error. On the other hand, the effect of days after germination on plant survival by species, including the radiation dose $x$ days to germination, was evaluated using a mixed linear model:

$y_{i j k}=\mu+g_{i}+T_{j}+(g T)_{i j}+\varepsilon_{i j k}$

where $y_{i j k}$ represents the percentage of plant survival $i$; at the gamma radiation dose; days after germination $j ; \mu$ represents the general mean; $g_{i}$ is the effect of the gamma radiation dose; $T_{j}$ is the effect of the days after germination; $(g T)_{i j}$ is the effect of the interaction of the gamma radiation dose and the days after germination; and $\varepsilon_{i j k}$ is the random error. This model was adjusted with homogeneous and heterogeneous variances for different days after germination. The model for correlation structure was selected using the Akaike information criterion. Homoscedasticity and heteroscedasticity were tested using the Likelihood Ratio Test.

\section{Conclusion}

Gamma radiation on affected the germination and seedling growth of seeds of wheat and triticale cultivars from Argentina. This effect was considerably higher in roots than in the aerial parts. Results also confirm the high sensitivity of wheat and triticale seeds to gamma radiation, even at twelve days after germination. For wheat, our results were contrary to previous studies which reported that gamma radiation leads to an improvement in the number and length of roots. For triticale, this result was novel because there is less evidence about the effect of gamma radiation on triticale. The effect of ${ }^{60} \mathrm{C}_{0}$ on seeds was probably due to the particular genetic conditions of wheat and triticale seeds used in Argentina. Further studies should be necessary to validate this hypothesis by comparing different gamma radiation doses with other wheat and triticale cultivars sown in Argentina.

\section{References}

Abbate PE, Dardanelli JL, Cantarero MG, Maturano M, Melchiori RJM, Suero EE (2004) Climatic and water availability effects on water-use efficiency in wheat. Crop Sci. 44:474-483.

Agha MKK, Bucklin RA, Lee WS, Mankin RW, Blount AS (2017) Effect of Drying Conditions on Triticale Seed Germination and Rice Weevil Infestation. T ASABE. 60:571575.

Ahloowalia B, Maluszynski M (2001) Induced mutations-A new paradigm in plant breeding. Euphytica. 118:167-173.

Araus J, Slafer G, Reynolds M, Royo C (2002) Plant breeding and drought in C3 cereals: what should we breed for? Ann Bot London. 89:925-940.
Blum A, Sinmena B, Ziv O (1980) An evaluation of seed and seedling drought tolerance screening tests in wheat. Euphytica. 29:727-736.

Borzouei A, Kafi M, Khazaei $H$, Naseriyan B, Majdabadi A (2010) Effects of gamma radiation on germination and physiological aspects of wheat (Triticum aestivum L.) seedlings. Pak J Bot. 42:2281-2290.

Castro N, Rufach H, Capellino F, Domínguez R, Paccapelo H (2011) Evaluación del rendimiento de forraje y grano de triticales y tricepiros. Rev Inv Agr Argentina. 37.

Donaire G, Bainotti C, Reartes F, Salines J, Fraschina J, Alberione E, Gómez D, Conde B (2016) Evaluación de cultivares y líneas de triticale en la EEA Marcos Juárez durante el año 2015:75.

FAOSTAT (2015) FAOSTAT Database-Agricultural Production, in: http://faostat3.fao.org/home/index_es.html?locale=es (Ed.).

Irfaq M, Nawab K (2001) Effect of gamma irradiation on some morphological characteristics of three wheat (Triticum aestivum L.) cultivars. J Biol Sci. 1:935-945.

ISTA. (1985) International rules for seed testing. Rules 1985. Seed Sci Technol. 13:299-513.

Jan S, Parween T, Siddiqi T (2012) Effect of gamma radiation on morphological, biochemical, and physiological aspects of plants and plant products. Environ Rev. 20:17-39.

Melki M, Marouani A (2010) Effects of gamma rays irradiation on seed germination and growth of hard wheat. Environ Rev. 8:307-310.

Miazek A, Bogdan J, Zagdańska B (2001) Effects of water deficit during germination of wheat seeds. Environ Chen Lett. 44:397-403.

Mirabella N, Abbate P, Ramirez I, Pontaroli A (2016) Genetic variation for wheat spike fertility in cultivars and early breeding materials. J Agr Sci. 154:13-22.

Miralles D, Spinedi M, Abeledo L, Abelleyra D (2007) Variability on photoperiod responses in Argentinean wheat cultivars differing in length of crop cycle. Processings of the 7th International Wheat Conference, 27 Nov - 2 Dic 2005, Mar del Plata, Argentina:599-609.

Paccapelo $H$, Ferreira V, Picca A, Ferrari E, Domínguez R, Grassi E, Ferreira A, di Santo H, Castillo E (2017) Triticale (x Triticosecale Wittmack): Rendimiento y sus componentes en un ambiente semiárido de Argentina. Chilean J Agric Anim. 33:45-58.

Pandini F., Carvalho F.I.F.d., Barbosa Neto J.F. (1997) Plant height reduction in populations of triticale ( $X$ triticosecale Wittmack) by induced mutations and artificial crosses. Braz J Genet. 20.

Sapra VT, Constantin MJ (1978) Seed radiosensitivity of a hexaploid triticale. Environ Exp Bot. 18:77-79.

Setter T, Waters I (2003) Review of prospects for germplasm improvement for waterlogging tolerance in wheat, barley and oats. Plant Soil. 253:1-34.

SIIA. (2016) Sistema Integrado de Información Agropecuaria, in: www.siia.gov.ar (Ed.), Buenos Aires - Argentina.

Singh B, Ahuja S, Singhal R, Babu PV (2013) Effect of gamma radiation on wheat plant growth due to impact on gas exchange characteristics and mineral nutrient uptake and utilization. J Radioanal Nucl Ch. 298:249-257.

Singh B, Datta P (2010) Gamma irradiation to improve plant vigour, grain development, and yield attributes of wheat. Radiat Phys Chem. 79:139-143. 
Singh N, Balyan H (2009) Induced mutations in bread wheat (Triticum aestivum L.) CV.'Kharchia 65'for reduced plant height and improve grain quality traits. Adven Biol Res. 3:215-221.

Slafer G.A., Andrade F.H. (1989) Genetic improvement in bread wheat (Triticum aestivum) yield in Argentina. Field Crop Res. 21:289-296.

Slafer GA, Araus JL, Royo C, Moral LFG (2005) Promising ecophysiological traits for genetic improvement of cereal yields in Mediterranean environments. Ann Apl Biol. 146:61-70.

Sparrow AH, Schwemmer SS, Bottino PJ (1971) The effects of external gamma radiation from radioactive fallout on plants with special reference to crop production. Radiat Bot. 11:85-118.
Vanzetti LS, Yerkovich N, Chialvo E, Lombardo L, Vaschetto L, Helguera M (2013) Genetic structure of Argentinean hexaploid wheat germplasm. Genet Mol Biol. 36:391-399.

Wang J, Yu Y, Tian X (2012) Effect of $Y$-ray irradiation on the germinating characteristics of wheat seed. Radiat Phys Chem. 81:463-465.

Wang Z-N, You R-I (2000) Changes in wheat germination following $\gamma$-ray irradiation: an in vivo electronic paramagnetic resonance spin-probe study. Environ Exp Bot. 43:219-225.

Wi SG, Chung BY, Kim J-S, Kim J-H, Baek M-H, Lee J-W, Kim YS (2007) Effects of gamma irradiation on morphological changes and biological responses in plants. 38:553-564.

Wrigley C, Batey I, Miskelly D (2016) Cereal Grains: Assessing and Managing Quality Elsevier Science. 